\title{
Effects of Various Antiepileptics Used to Alleviate Neuropathic Pain on Compound Action Potential in Frog Sciatic Nerves: Comparison with Those of Local Anesthetics
}

\author{
Yuhei Uemura, ${ }^{1,2}$ Tsugumi Fujita, ${ }^{1}$ Sena Ohtsubo, ${ }^{1}$ Naomi Hirakawa, ${ }^{2}$ \\ Yoshiro Sakaguchi, ${ }^{2}$ and Eiichi Kumamoto ${ }^{1}$ \\ ${ }^{1}$ Department of Physiology, Saga Medical School, Saga 849-8501, Japan \\ ${ }^{2}$ Department of Anesthesiology \& Critical Care Medicine, Saga Medical School, Saga 849-8501, Japan \\ Correspondence should be addressed to Eiichi Kumamoto; kumamote@cc.saga-u.ac.jp
}

Received 3 October 2013; Revised 24 December 2013; Accepted 7 January 2014; Published 24 February 2014

Academic Editor: James Stockand

Copyright (C) 2014 Yuhei Uemura et al. This is an open access article distributed under the Creative Commons Attribution License, which permits unrestricted use, distribution, and reproduction in any medium, provided the original work is properly cited.

\begin{abstract}
Antiepileptics used for treating neuropathic pain have various actions including voltage-gated $\mathrm{Na}^{+}$and $\mathrm{Ca}^{2+}$ channels, glutamatereceptor inhibition, and $\mathrm{GABA}_{\mathrm{A}}$-receptor activation, while local anesthetics are also used to alleviate the pain. It has not been fully examined yet how nerve conduction inhibitions by local anesthetics differ in extent from those by antiepileptics. Fast-conducting compound action potentials (CAPs) were recorded from frog sciatic nerve fibers by using the air-gap method. Antiepileptics (lamotrigine and carbamazepine) concentration dependently reduced the peak amplitude of the CAP $\left(\mathrm{IC}_{50}=0.44\right.$ and $0.50 \mathrm{mM}$, resp.). Carbamazepine analog oxcarbazepine exhibited an inhibition smaller than that of carbamazepine. Antiepileptic phenytoin $(0.1 \mathrm{mM})$ reduced CAP amplitude by $15 \%$. On the other hand, other antiepileptics (gabapentin, sodium valproate, and topiramate) at $10 \mathrm{mM}$ had no effect on CAPs. The CAPs were inhibited by local anesthetic levobupivacaine $\left(\mathrm{IC}_{50}=0.23 \mathrm{mM}\right)$. These results indicate that there is a difference in the extent of nerve conduction inhibition among antiepileptics and that some antiepileptics inhibit nerve conduction with an efficacy similar to that of levobupivacaine or to those of other local anesthetics (lidocaine, ropivacaine, and cocaine) as reported previously. This may serve to know a contribution of nerve conduction inhibition in the antinociception by antiepileptics.
\end{abstract}

\section{Introduction}

Neuropathic pain, one of chronic pains, which occurs as a result of the damage of the PNS or CNS, is characterized by a hyperexcitability of neurons near the injured neuronal tissues [1]. This type of pain is often resistant to analgesics such as nonsteroidal anti-inflammatory drugs and opioids and thus requires other kinds of drugs including antiepileptics for antinociception [2-4]. Local anesthetics such as lidocaine and bupivacaine have been also used for the treatment of the neuropathic pain with an expectation of the inhibition of nerve action potential (AP) conduction in humans [5-7] and animals $[8,9]$.

Antiepileptics have various actions including voltagegated $\mathrm{Na}^{+}$and $\mathrm{Ca}^{2+}$ channels, glutamate-receptor inhibition, and $\mathrm{GABA}_{\mathrm{A}}$-receptor activation $[4,10]$. As indicated by the local anesthetics' actions, nerve conduction inhibition is important for antiepileptics to alleviate neuropathic pain. To our knowledge, however, it has not been systematically examined yet how AP inhibitions by various antiepileptics differ in extent from each other and also how the inhibitions are distinct from those of local anesthetics. We have previously reported that local anesthetics (lidocaine, ropivacaine, cocaine, procaine, and tetracaine) reduce the peak amplitude of compound AP (CAP), which is fast conducting and sensitive to a voltage-gated $\mathrm{Na}^{+}$-channel blocker tetrodotoxin, in the frog sciatic nerve [11-14]. In order to know the extents of nerve conduction inhibitions by antiepileptics and local anesthetics, we examined the effects of various antiepileptics and a local anesthetic levobupivacaine (which exhibits a 
lower risk of cardiovascular and CNS toxicity than racemic bupivacaine) [15] on CAPs recorded from the frog sciatic nerve by using the air-gap method.

\section{Materials and Methods}

This study was approved by the Animal Care and Use Committee of Saga University.

2.1. Frog Sciatic Nerves. The method used for obtaining frog sciatic nerve preparation has been described previously [1114]. In brief, either sex of frogs was decapitated and then pithed; thereafter the sciatic nerve was dissected from the lumbar plexus to the knee in Ringer's solution. The isolated sciatic nerve was carefully desheathed under a binocular microscope and then loosely placed in five platinum wires, which were glued to a Lucite plate, where the two ends of the nerve were tied to the wires by using threads. The plate was put on a beaker having Ringer's solution in which the sciatic nerve was soaked. The composition of Ringer's solution used was (mM): $\mathrm{NaCl}, 115.5 ; \mathrm{KCl}, 2.0 ; \mathrm{CaCl}_{2}, 1.8 ; \mathrm{Na}_{2} \mathrm{HPO}_{4}, 1.3$; and $\mathrm{NaH}_{2} \mathrm{PO}_{4}, 0.7(\mathrm{pH}=7.0)$.

2.2. Compound Action Potential. As performed previously [11-14], the Lucite plate having platinum wires attached with the sciatic nerve was moved from the beaker containing Ringer's solution to a vacant one and then CAPs were recorded in air using a preamplifier. Here, two of the platinum wires were used to record CAPs and the other two were for stimulating the sciatic nerve at a frequency of $1 \mathrm{~Hz}$ with a stimulator. This procedure was quickly performed at a time interval of $2 \mathrm{~min}$. The data were monitored on a storage oscilloscope while being recorded on a thermal array recorder. Stimulating the sciatic nerve produced a CAP following a stimulus artifact; the peak amplitude of the CAP was measured as a difference between baseline and CAP peak level, as done previously [11-14]. The stimulus strength used to obtain a maximal amplitude CAP was in a range of 0.4$2.7 \mathrm{~V}$. A conduction velocity $(\mathrm{CV})$ value was determined by using the fifth wire as an additional stimulation site and then by measuring a change in time between stimulus artifact and the peak of CAP. All experiments were carried out at room temperature.

2.3. Drugs. Drugs used were lamotrigine (Toronto Research Chemicals Inc., Canada), carbamazepine, phenytoin, sodium valproate (Wako Pure Chemical Industries, Ltd., Osaka, Japan), oxcarbazepine, gabapentin, topiramate, and bupivacaine hydrochloride (Tokyo Chemical Industries, Co. Ltd., Tokyo, Japan). Levobupivacaine hydrochloride was kindly gifted by Maruishi Pharmaceutical Co. Ltd. (Osaka, Japan). All of drugs (except for gabapentin, topiramate, and sodium valproate which were directly dissolved in Ringer's solution) were first dissolved in dimethyl sulfoxide (DMSO) as a stock solution and then diluted to the desired concentrations in Ringer's solution immediately before use, where the concentration of DMSO was less than $2 \%$. Drugs at concentrations larger than $10 \mathrm{mM}$ were not tested, because a change in osmotic pressure may affect CAPs. The $\mathrm{pH}$ of Ringer's solution containing drugs was adjusted to 7.0 with $\mathrm{NaOH}$.

2.4. Data Analysis. Concentration-response curve for the reduction of the peak amplitude of CAP in the sciatic nerve soaked with a drug was analyzed using the following Hill equation:

$$
\begin{aligned}
& \text { CAP amplitude }(\% \text { of control) } \\
& =\frac{100}{1+\left([\text { Drug }] / \mathrm{IC}_{50}\right)^{n_{\mathrm{H}}}},
\end{aligned}
$$

where [Drug] is drug concentration, $\mathrm{IC}_{50}$ is the concentration of drug for half-maximal inhibition, and $n_{\mathrm{H}}$ is the Hill coefficient.

Data were indicated as mean \pm SEM and statistical significance was set at $P<0.05$ using a paired or unpaired Student's $t$-test. In all cases $n$ refers to the number of sciatic nerves studied. The peak amplitude of CAP before drug application was denoted as control.

\section{Results}

Effects of drugs on the CAPs were examined in a total of 175 sciatic nerves, and the peak amplitude of the CAPs averaged to be $21.9 \pm 0.5 \mathrm{mV}(n=175)$. When measured in some of the nerves, the CAPs had CV values of $26.4 \pm 0.7 \mathrm{~m} / \mathrm{s}$ $(n=108)$, values comparable to those reported previously [11-14]. DMSO at 2\%, a maximal concentration used in the present study, did not affect CAPs. The peak amplitude of CAP at 20 min after soaking with DMSO (2\%) was $98.8 \pm 1.6 \%$ $(n=5)$ of control $(19.0 \pm 3.7 \mathrm{mV})$; this percentage value was not significantly different from $100 \%(P>0.05)$.

\subsection{Effects of Antiepileptics on Compound Action Potential} in Frog Sciatic Nerves. We first examined the effect of a phenyltriazine derivative (lamotrigine; 3,5-diamino-6-(2,3dichlorophenyl)-1,2,4-triazine; Figure 1(a)), which is known to inhibit voltage-gated $\mathrm{Na}^{+}$channels [16] and to relieve central poststroke pain and painful diabetic polyneuropathy [3], on CAPs in the frog sciatic nerve. As seen in Figure 1(b), soaking the sciatic nerve into lamotrigine $(0.5 \mathrm{mM})$-containing Ringer's solution reduced the peak amplitude of the CAP in a partially reversible manner. Figure 1(c) demonstrates an average of the time courses of a change in CAP peak amplitude following soaking into lamotrigine $(0.5 \mathrm{mM})$, relative to control, which is obtained from five sciatic nerves. The lamotrigine $(0.5 \mathrm{mM})$-induced reduction in CAP peak amplitude was close to a steady effect at $20 \mathrm{~min}$ after the soaking, where the peak amplitude of CAP was $44.0 \pm 6.1 \%$ $(n=5 ; P<0.05)$ of control $(21.5 \pm 2.0 \mathrm{mV})$. This percentage value was not significantly different from one $(47.5 \pm 7.4 \%$; $n=5)$ at $18 \mathrm{~min}$ after the soaking $(P>0.05)$. At least $30 \mathrm{~min}$ after soaking the sciatic nerve into lamotrigine-free solution, the CAP amplitude partially recovered to control level, as shown in Figures 1(b) and 1(c). The peak amplitude of CAP at $30 \mathrm{~min}$ after washout of lamotrigine was $82.4 \pm 4.6 \%(n=5)$ of 


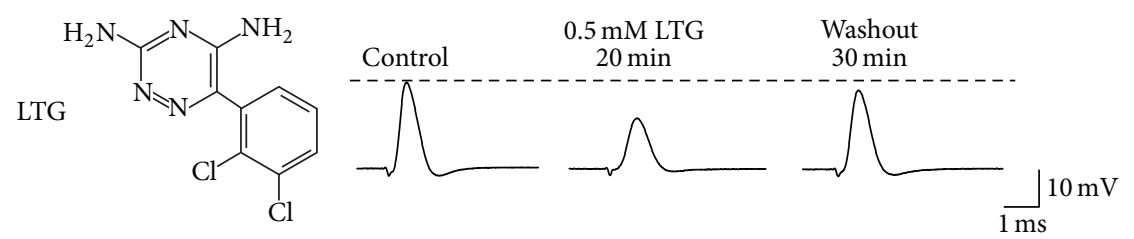

(a)

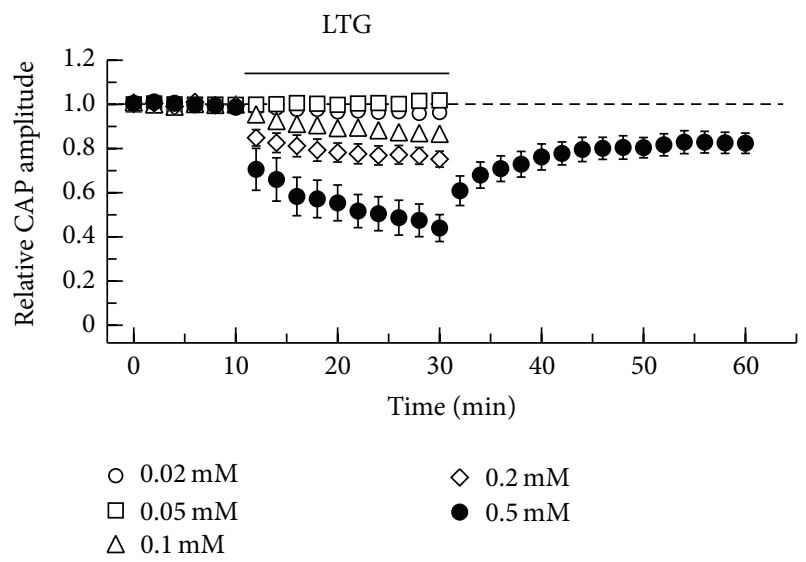

(c) (b)

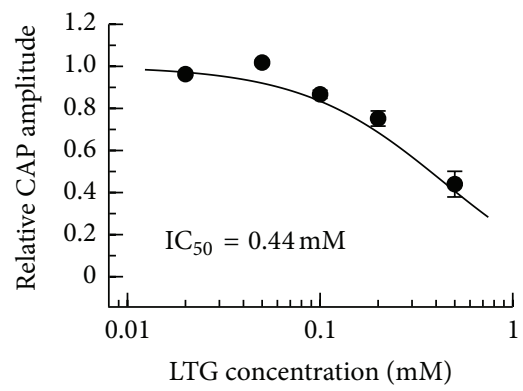

(d)

FIGURE 1: Effect of lamotrigine (LTG) on compound action potentials (CAPs) recorded from frog sciatic nerve fibers. (a) The chemical structure of LTG. (b) Recordings of CAPs before (control), at $20 \mathrm{~min}$ after exposure to LTG, and thereafter 30 min in the absence of LTG. (c) Average time courses of changes in CAP peak amplitude following exposure to LTG at $0.02-0.5 \mathrm{mM}$ for 20 min, relative to those before the soaking (each point: $n=5$ ). Relative CAP amplitude after washout of LTG is shown only for data at $0.5 \mathrm{mM}$. In this and subsequent figures, each point with vertical bars represents the mean and SEM. If the SEM of the values is smaller than the size of the symbol, the vertical bar is not shown. (d) The CAP inhibition produced by LTG is concentration dependent. The peak amplitudes of CAPs recorded from sciatic nerve fibers treated with LTG at various concentrations for $20 \mathrm{~min}$, relative to control, which were plotted against LTG concentration (each point: $n=5$ ). This concentration-response curve was drawn according to the Hill equation (half-maximal inhibitory concentration $\left(\mathrm{IC}_{50}\right)=$ $0.44 \mathrm{mM}$; Hill coefficient $\left(n_{\mathrm{H}}\right)=1.2$ ).

control; this percentage value was significantly smaller than $100 \%(P<0.05)$. Figure $1(\mathrm{c})$ demonstrates the time courses of changes in CAP peak amplitude with an increase in time after soaking the sciatic nerve into lamotrigine at various concentrations ranging from $0.02 \mathrm{mM}$ to $0.5 \mathrm{mM}$ (a maximally soluble concentration). The rate of the CAP peak amplitude reduction produced by lamotrigine was enhanced in extent with an increase in its concentration. As seen in Figure 1(c), CAP amplitude reduction after 20 min treatment increased in extent with an increase in lamotrigine concentration. The concentration-response curve for the lamotrigine-induced CAP amplitude reduction obtained from many nerve trunks $(n=25)$ is given in Figure $1(\mathrm{~d})\left(\mathrm{IC}_{50}=0.44 \mathrm{mM}\right)$.

We next examined the effect of carbamazepine (an iminostilbene derivative; 5H-dibenz $[\mathrm{b}, \mathrm{f}]$ azepine-5carboxamide; Figure 2(a)(A)), which is known to inhibit voltage-gated $\mathrm{Na}^{+}$channels [17] while being different in chemical structure from lamotrigine, on frog CAPs. Carbamazepine is reported to be effective to relieve trigeminal neuralgia [18, 19]. Figure 2(a)(B) demonstrates an average of the time courses of a change in CAP peak amplitude following soaking into carbamazepine $(0.5 \mathrm{mM})$, relative to control, which is obtained from five sciatic nerves. Like lamotrigine, carbamazepine exhibited an effect close to steady one of CAP amplitude reduction within $20 \mathrm{~min}$ after the soaking, where the peak amplitude reduced to $65.2 \pm 5.0 \%(P<0.05)$ of control $(20.9 \pm 2.6 \mathrm{mV} ; n=5)$. This percentage value was not significantly different from one $(67.8 \pm 5.2 \% ; n=5)$ at $18 \mathrm{~min}$ after the soaking $(P>0.05)$. This inhibitory action was reversible, as different from that of lamotrigine. The peak amplitude of CAP at $30 \mathrm{~min}$ after washout of carbamazepine was $98.2 \pm 1.7 \%(n=5)$ of control; this percentage value was significantly not different from $100 \%(P>0.05)$. Figure $2(\mathrm{a})(\mathrm{C})$ demonstrates the effects of carbamazepine in a wide concentration range of $0.05-1 \mathrm{mM}$ on CAPs. The CAP peak amplitude reduction produced by carbamazepine was enhanced in extent with an increase in its concentration $\left(\mathrm{IC}_{50}=0.50 \mathrm{mM}\right)$.

We have previously reported that CAP inhibitions produced by tramadol and mono-O-demethyl tramadol [11] and also by morphine, codeine, and ethylmorphine [12] are related in extent to their chemical structures such that this magnitude is enhanced with an increase in the number of $-\mathrm{CH}_{2}$ in a benzene ring. We, therefore, investigated the effect of oxcarbazepine (10,11-dihydro-10-oxo$5 \mathrm{H}$-dibenz [b,f] azepine-5-carboxamide; Figure 2(b)(A)) [20], where there is a keto substitution at the 10,11 position of the dibenzazepine nucleus of carbamazepine, on frog CAPs. 
(A)

CBZ

(B)<smiles>NC(=O)N1c2ccccc2C=Cc2ccccc21</smiles>

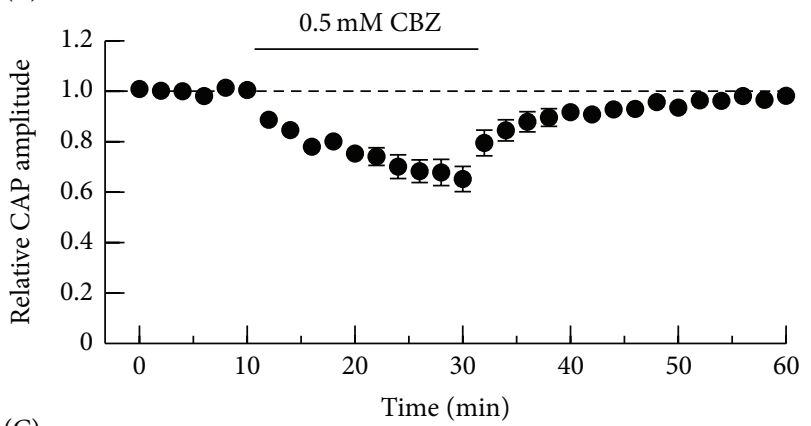

(C)

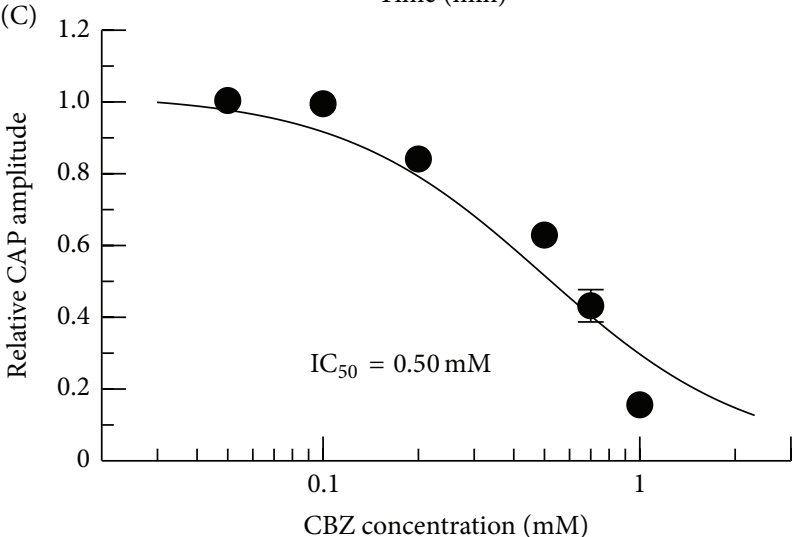

(D)

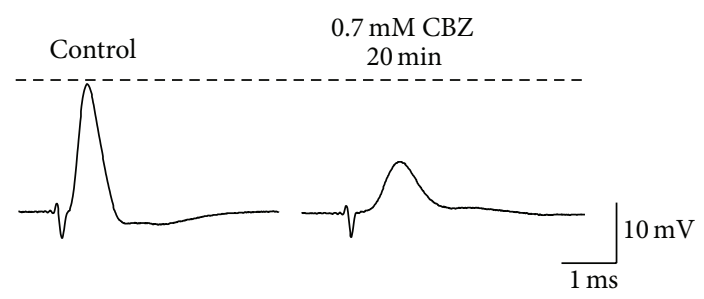

(a)
(A)<smiles></smiles>

(B)
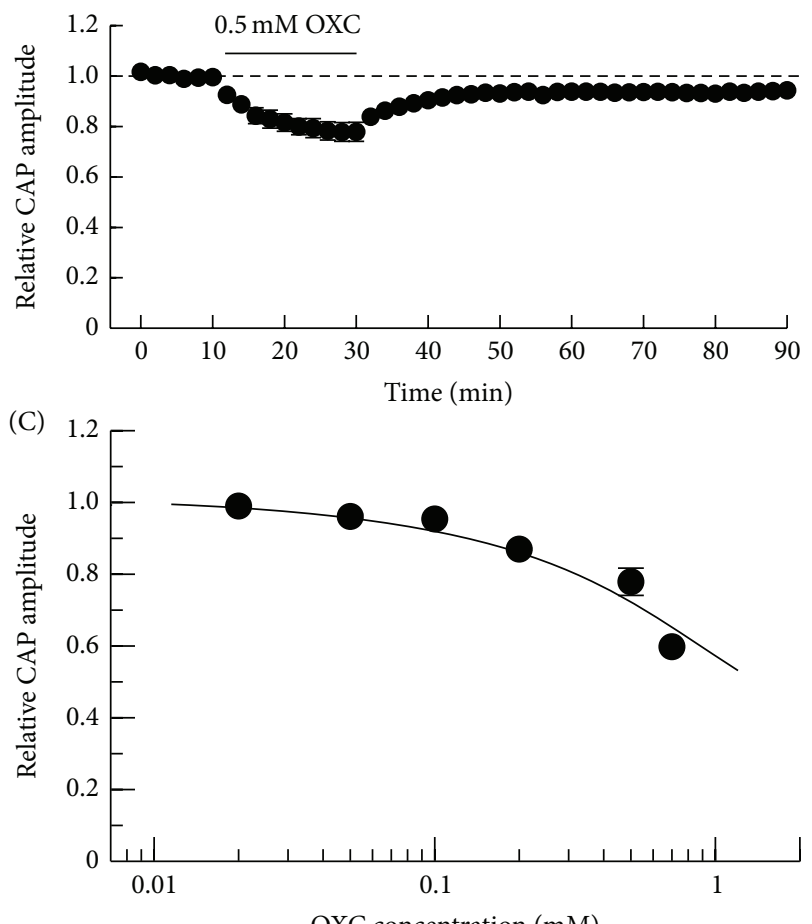

(D)

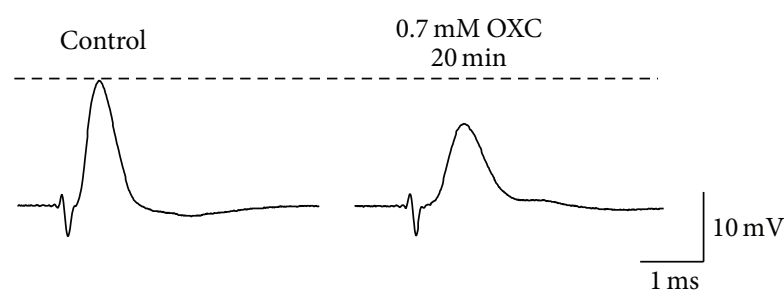

(b)

Figure 2: Effects of carbamazepine (CBZ) and oxcarbazepine (OXC) on CAPs recorded from frog sciatic nerve fibers. ((a)(A)), ((b)(A)) The chemical structures of CBZ ((a)(A)) and OXC ((b)(A)). ((a)(B)), ((b)(B)) Average time course of changes in CAP peak amplitude following exposure to CBZ $((\mathrm{a})(\mathrm{B}))$ or OXC $((\mathrm{b})(\mathrm{B}))$ for $20 \mathrm{~min}$, relative to those before the soaking (each point: $n=5)$. $((\mathrm{a})(\mathrm{C}))$, $((\mathrm{b})(\mathrm{C}))$ The peak amplitudes of CAPs recorded from sciatic nerve fibers treated with CBZ $(((\mathrm{a})(\mathrm{C}))$; each point: $n=5-9)$ or OXC $(((\mathrm{b})(\mathrm{C}))$; $n=5)$ at various concentrations for $20 \mathrm{~min}$, relative to control, which were plotted against its concentration. The concentration-response curve in ((a)(C)) was drawn according to the Hill equation $\left(\mathrm{IC}_{50}=0.50 \mathrm{mM}, n_{\mathrm{H}}=1.3\right)$. ((a)(D)), ((b)(D)) Recordings of CAPs before and at $20 \mathrm{~min}$ after exposure to $\mathrm{CBZ}((\mathrm{a})(\mathrm{D}))$ or OXC $((\mathrm{b})(\mathrm{D}))$ at $0.7 \mathrm{mM}$. Solid line in the graph of $((\mathrm{b})(\mathrm{C}))$ was arbitrarily drawn.

This antiepileptic is known to be effective in relieving painful diabetic neuropathy [3] and trigeminal neuralgia [19]. Oxcarbazepine reduced the CAP peak amplitude in a partially reversible manner (Figure $2(\mathrm{~b})(\mathrm{B})$ ), an action different from that of carbamazepine while similar to that of lamotrigine. The peak amplitude of CAP at $60 \mathrm{~min}$ after washout of oxcarbazepine was $94.3 \pm 1.5 \%(n=5)$ of control $(21.6 \pm$ $0.8 \mathrm{mV})$; this percentage value was significantly smaller than
$100 \%(P<0.05)$. Oxcarbazepine activity was concentration dependent in a range of $0.02 \mathrm{mM}$ to $0.7 \mathrm{mM}$ (a maximally soluble concentration), as seen in Figure $2(\mathrm{~b})(\mathrm{C})$. When compared at $0.7 \mathrm{mM}$, carbamazepine inhibited CAPs more effectively than oxcarbazepine (Figures 2(a)(D) and 2(b)(D)); CAP amplitude reduction by carbamazepine $(43.2 \pm 4.5 \%$ of control, $n=5$ ) was larger than that of oxcarbazepine $(59.8 \pm 1.8 \%$ of control, $n=5 ; P<0.05)$. 


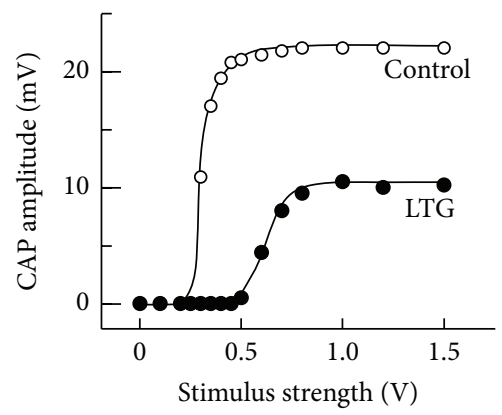

(a)

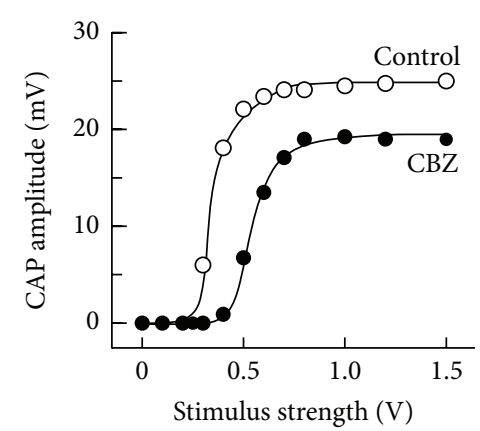

(b)

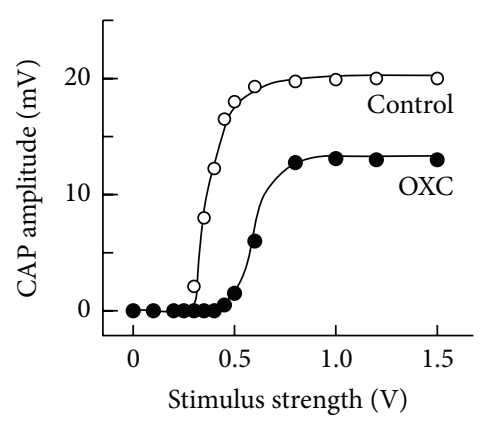

(c)

FIGURE 3: The peak amplitudes of CAPs in the absence (control) and presence of LTG (a), CBZ (b), or OXC (c); each is 0.5 mM, which are plotted against stimulus strength used to elicit the CAPs. Solid lines in the graphs of (a)-(c) were arbitrarily drawn.

Figure 3 demonstrates the effects of lamotrigine, carbamazepine, and oxcarbazepine (each $0.5 \mathrm{mM}$ ) on CAPs elicited at various stimulus strengths given to the sciatic nerve. Each of their inhibitory effects was seen for CAPs evoked at a maximal stimulus strength, while a threshold to elicit CAPs was increased by the antiepileptic. Each of the results was obtained in three other nerves. These results may be consistent with the observations that the antiepileptics shift the steady-state inactivation of $\mathrm{Na}^{+}$-channel currents to a more negative membrane potential [21-23].

A well-known antiepileptic phenytoin (hydantoin derivative; 5,5-diphenylhydantoin; Figure 4(a); which is known to inhibit voltage-gated $\mathrm{Na}^{+}$channels [24] and to relieve paroxysm in trigeminal neuralgia [18]) at $0.1 \mathrm{mM}$ (a maximally soluble concentration) inhibited frog CAPs in a partially reversible manner (Figure $4(\mathrm{~b})(\mathrm{A})$ ). CAP peak amplitude at $20 \mathrm{~min}$ after the soaking to phenytoin was $83.5 \pm 1.8 \%(n=7$; $P<0.05)$ of control $(16.2 \pm 1.7 \mathrm{mV})$. This percentage value was also close to the steady one of CAP amplitude reduction, because this value was not significantly different from one $(84.0 \pm 1.9 \% ; n=7)$ at $18 \mathrm{~min}$ after the soaking $(P>0.05)$. The inhibitory action of phenytoin was concentration dependent, as seen in Figure 4(b)(B).

On the other hand, other antiepileptics, gabapentin (1-(aminomethyl)cyclohexaneacetic acid; which is related to GABA in chemical structure and reportedly relieves post-herpetic neuralgia [18]), topiramate (2,3:4,5-bis-O(1-methylethylidene)- $\beta$-D-fructopyranose sulfamate, which relieves various neuropathic pains including trigeminal neuralgia and intercostal neuralgia [4]), and sodium valproate (2-propylpentanoic acid sodium salt; Figure 4(a), which provides improvement in diabetic neuropathic pain [4]), at a high concentration such as $10 \mathrm{mM}$, had no effect on CAPs (Figures 4(c), 4(d), and 4(e)). CAP amplitudes at $20 \mathrm{~min}$ after the soaking to gabapentin, topiramate, and sodium valproate were $97.3 \pm 0.8 \%(P>0.05 ; n=5), 96.0 \pm 1.2 \%(P>0.05$; $n=5)$, and $94.2 \pm 2.4 \%(P>0.05 ; n=5)$ of control, respectively.

3.2. Effect of Levobupivacaine on Compound Action Potential in Frog Sciatic Nerves. In order to know whether the antiepileptics exhibit an AP inhibition comparable to those of local anesthetics, we next examined the effect of levobupivacaine on frog CAPs. Levobupivacaine at $0.5 \mathrm{mM}$ reversibly reduced CAP peak amplitude, as seen in Figure 5(a). Figure 5(b) demonstrates an average of the time courses of a change in CAP peak amplitude following soaking into levobupivacaine, relative to control. Levobupivacaine $(0.5 \mathrm{mM})$ exhibited an effect close to the steady one of CAP amplitude reduction at $20 \mathrm{~min}$ after the soaking, where the peak amplitude reduced to $22.0 \pm 3.6 \%(n=7 ; P<0.05)$ of control $(22.2 \pm 3.7 \mathrm{mV})$. This percentage value was not significantly different from one $(24.0 \pm 4.0 \% ; n=7)$ at $18 \mathrm{~min}$ after the soaking $(P>0.05)$. The peak amplitude of CAP at $60 \mathrm{~min}$ after washout of levobupivacaine was $95.4 \pm 5.2 \%$ $(n=6)$ of control; this percentage value was significantly not different from $100 \%(P>0.05)$. The extent and rate of the CAP peak amplitude reduction produced by levobupivacaine were enhanced with an increase in its concentration in a range of 0.05-1 mM (Figures 5(b) and 5(c) (A,B); $\mathrm{IC}_{50}=0.23 \mathrm{mM}$ ).

Since levobupivacaine is known to be less effective in inhibiting CAPs than racemic bupivacaine [25], we next examined the effect of bupivacaine $(0.5 \mathrm{mM})$ on frog CAPs. CAP peak amplitude was reduced to $23.5 \pm 11.8 \%(n=4$; $P<0.05)$ of control $(23.6 \pm 3.1 \mathrm{mV})$ at $4 \mathrm{~min}$ after the soaking (not shown). This percentage value was significantly smaller than levovupivacaine's one $(55.1 \pm 3.2 \%, n=7 ; P<0.05)$. The treatment with bupivacaine for 20 min resulted in a complete block of CAPs.

\section{Discussion}

The present study revealed that lamotrigine and carbamazepine concentration dependently reduce the peak amplitude of the CAP with the $\mathrm{IC}_{50}$ values of 0.44 and $0.50 \mathrm{mM}$, respectively. This $\mathrm{IC}_{50}$ value for lamotrigine was similar to that $(0.641 \mathrm{mM}$ at $-90 \mathrm{mV})$ in inhibiting TTX-sensitive human brain type IIA $\mathrm{Na}^{+}$channels expressed in Chinese hamster ovary cells [16]. Consistent with our observation that lamotrigine and carbamazepine had comparable $\mathrm{IC}_{50}$ values, they reduced $\mathrm{Na}^{+}$-channel current amplitude in N4TG1 mouse neuroblastoma cells with $\mathrm{IC}_{50}$ values similar to each other [21]. Oxcarbazepine at $0.5 \mathrm{mM}$ reduced CAP peak amplitude by $20 \%$; this activity was much smaller than 


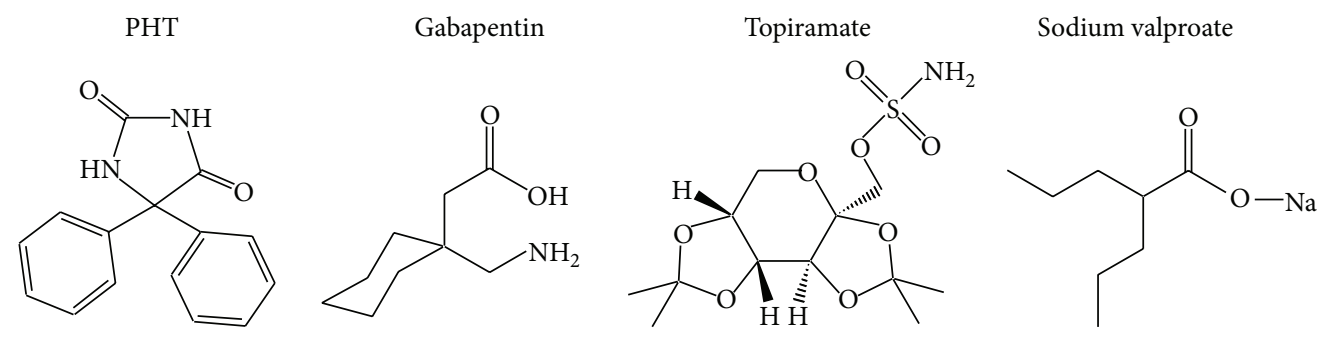

(a)
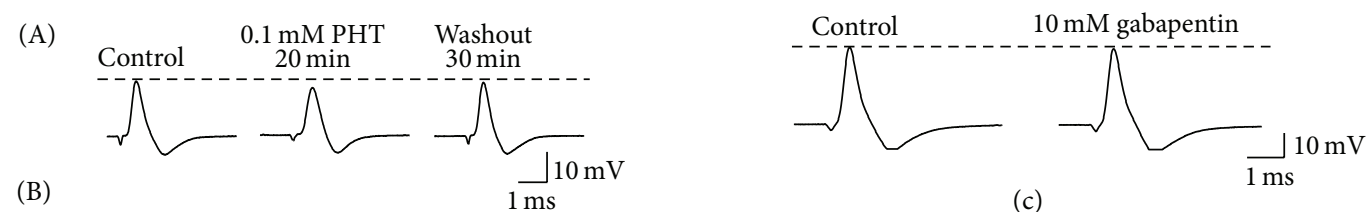

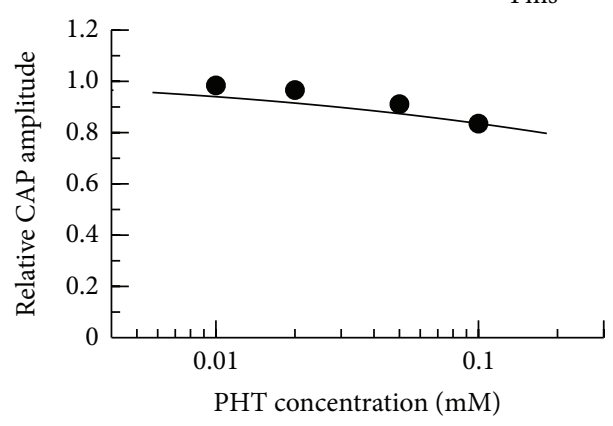

(b)

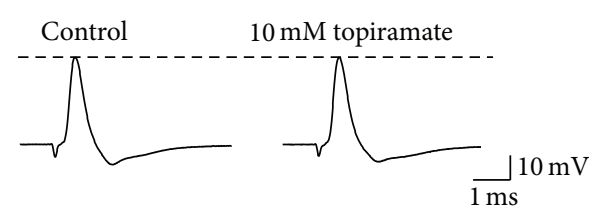

(d)

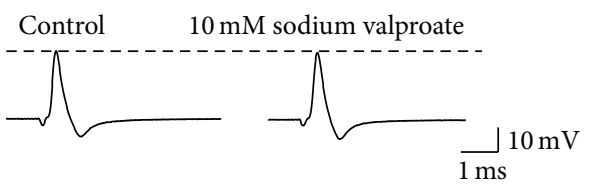

(e)

FIGURE 4: Effects of phenytoin (PHT), gabapentin, topiramate, and sodium valproate on CAPs recorded from frog sciatic nerve fibers. (a) The chemical structures of PHT, gabapentin, topiramate, and sodium valproate. (b) PHT minimally inhibits CAPs in a partially reversible manner. ((b)(A)) Recordings of CAPs before, at 20 min after exposure to PHT, and thereafter 30 min in the absence of PHT. ((b)(B)) The peak amplitudes of CAPs recorded from sciatic nerve fibers treated with PHT at various concentrations for 20 min, relative to control, which were plotted against PHT concentration (each point: $n=5-7)$. The line was arbitrarily drawn. ((c), (d), and (e)) Recordings of CAPs before and at 20 min after exposure to gabapentin (c), topiramate (d), and sodium valproate (e). They hardly affected CAPs.

that for $\mathrm{Na}^{+}$-channel inhibition in differentiated NG108-15 neuronal cells $\left(\mathrm{IC}_{50}=3.1 \mu \mathrm{M}\right)$ [23]. Smaller CAP inhibition by oxcarbazepine than carbamazepine in the present study may be consistent with the observation that oxcarbazepine was less effective than carbamazepine in inhibiting seizures induced by maximal electroshock in rats [20]. Phenytoin at $0.1 \mathrm{mM}$ reduced CAP peak amplitude by only $15 \%$. This phenytoin activity was less than those for rat cortical and human type IIA $\mathrm{Na}^{+}$-channel currents (60-90\% amplitude reduction at $-60 \mathrm{mV}$ by $0.1 \mathrm{mM}$ phenytoin) [16, 24]. As different from ours, phenytoin inhibited $\mathrm{Na}^{+}$channels in N4TG1 mouse neuroblastoma cells with an $\mathrm{IC}_{50}$ value comparable to that of lamotrigine [21], and phenytoin, lamotrigine, and carbamazepine were suggested to bind to a common binding site of $\mathrm{Na}^{+}$channels in rat hippocampal CA1 neurons [22]. A sensitivity of voltage-gated $\mathrm{Na}^{+}$channels to phenytoin may be distinct in extent among different types of the channel. This idea is supported by the observation that there was a difference in phenytoin actions among human $\mathrm{Na}_{\mathrm{v}} 1.1, \mathrm{Na}_{\mathrm{v}} 1.2$, $\mathrm{Na}_{\mathrm{v}} 1.3$, and $\mathrm{Na}_{\mathrm{v}} 1.4 \alpha$-subunits expressed in HEK293 cells [26]. Alternatively, there was a difference in the properties and accessibilities of $\mathrm{Na}^{+}$channels between frog and rat myelinated nerves [27].

On the other hand, gabapentin and sodium valproate at $10 \mathrm{mM}$ had no effect on frog CAPs. The observation that gabapentin and sodium valproate were less effective than phenytoin in inhibiting CAPs was similar to that for human type IIA $\mathrm{Na}^{+}$channels [16]. Xie et al. [16] have reported that gabapentin at concentrations of less than $3 \mathrm{mM}$ hardly affects the human $\mathrm{Na}^{+}$channels. The antinociceptive action of gabapentin has been mainly attributed to bind to the $\alpha_{2} \delta$-subunit of voltage-gated $\mathrm{Ca}^{2+}$ channels, resulting in a decrease in $\mathrm{Ca}^{2+}$ entry in nerve terminals which in turn inhibits the release of neurotransmitters from there [28]. Although Zona et al. [29] reported that topiramate reduces TTX-sensitive $\mathrm{Na}^{+}$-channel current amplitude in rat cerebellar granule cells with an $\mathrm{IC}_{50}$ value of $48.9 \mu \mathrm{M}$, frog CAPs were not affected by this drug at $10 \mathrm{mM}$. Such a result may be due to a distinction in topiramate sensitivity among different types or phosphorylation states of $\mathrm{Na}^{+}$channels [30]. Each of sodium valproate and topiramate appears to exhibit antinociceptive actions through several mechanisms 

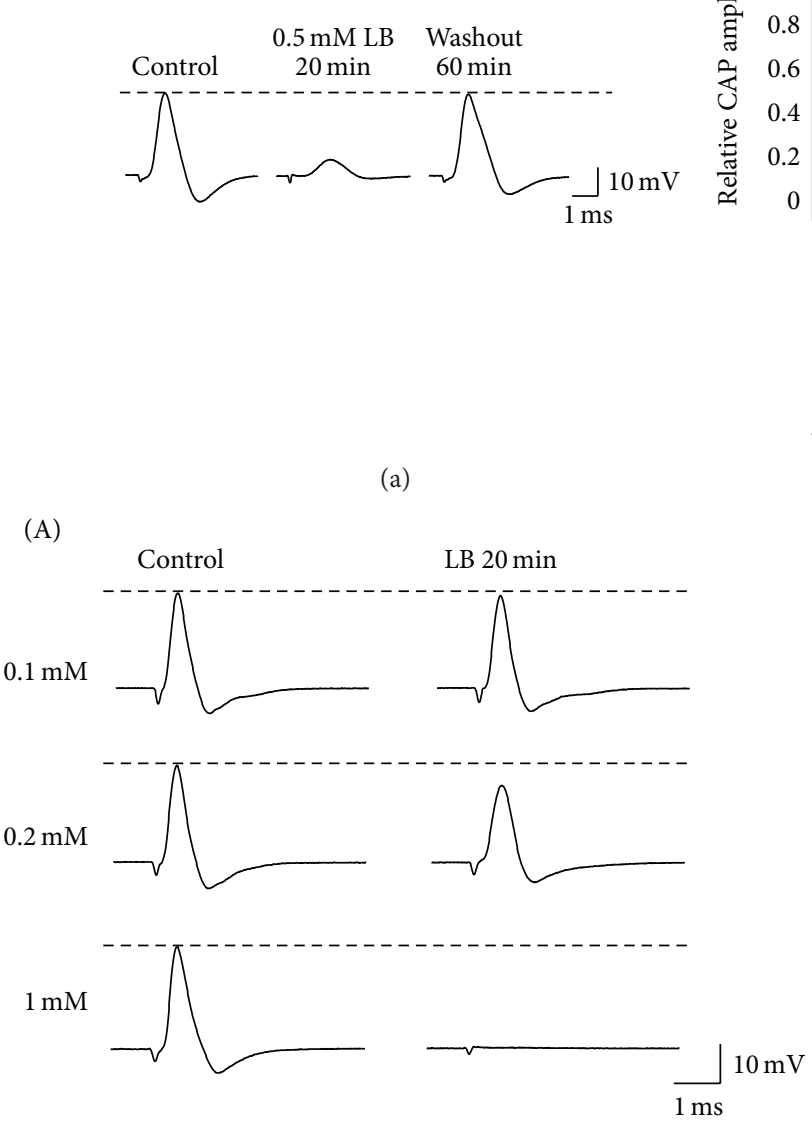

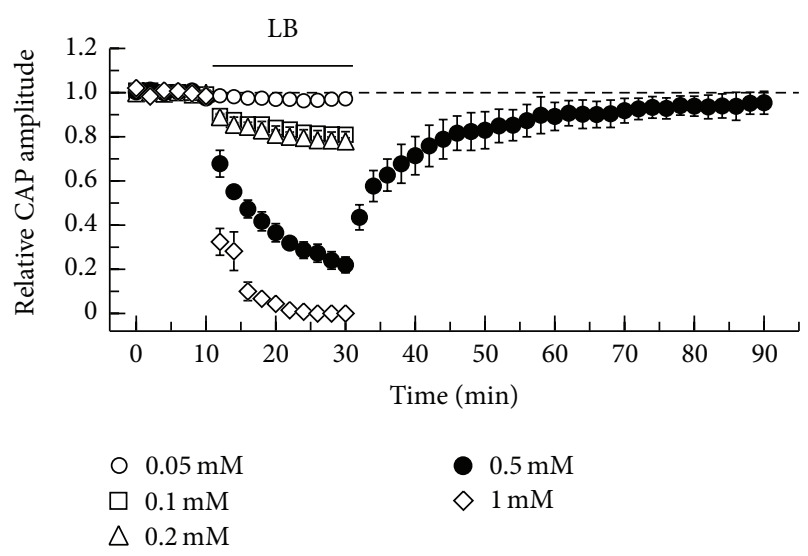

(b)

(B)

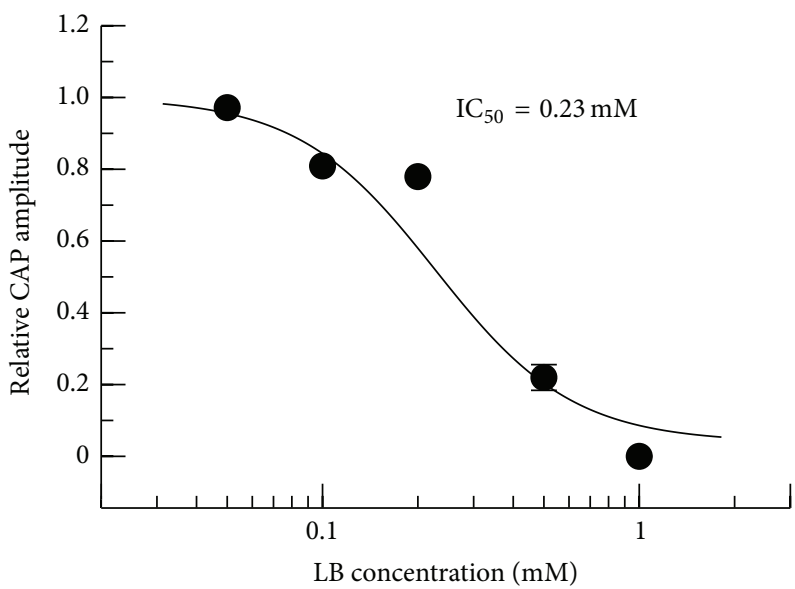

(c)

FIGURE 5: Effect of a local anesthetic levobupivacaine (LB) on CAPs recorded from frog sciatic nerve fibers. ((a), (b)) LB reduces CAP peak amplitude in a reversible manner. (a) Recordings of CAPs before, at $20 \mathrm{~min}$ after exposure to LB, and thereafter 60 min in the absence of LB. (b) Average time courses of changes in CAP peak amplitude following exposure to LB at $0.05-1 \mathrm{mM}$ for 20 min, relative to those before the soaking (each point: $n=4-7$ ). Relative CAP amplitude after washout of LB is shown only for data at $0.5 \mathrm{mM}$. (c) The CAP inhibition produced by LB is concentration dependent. ((c)(A)) Recordings of CAPs before and at 20 min after exposure to LB at 0.1, 0.2, and $1 \mathrm{mM}$. ((c)(B)) The peak amplitudes of CAPs recorded from sciatic nerve fibers treated with LB at various concentrations for 20 min, relative to control, which were plotted against LB concentration (each point: $n=4-7$ ). This concentration-response curve was drawn according to the Hill equation $\left(\mathrm{IC}_{50}=0.23 \mathrm{mM} ; n_{\mathrm{H}}=2.0\right)$.

including an increase in $\mathrm{GABA}_{\mathrm{A}}$-receptor responses [31, 32]. It is possible that the antinociceptions by topiramate and also lamotrigine are mediated by glutamate-receptor inhibition, because topiramate inhibits GluK1 (GluR5) kainate receptors in rat basolateral amygdala neurons [33] and lamotrigine inhibits AMPA receptors in rat dentate gyrus granule cells [34]. Antiepileptics having an ability to inhibit frog CAPs had a tendency to exhibit antinociception in a persistent pain model; when intraperitoneally applied in rats, lamotrigine, carbamazepine, and oxcarbazepine produced analgesic effects in the second phase of the formalin test, whereas phenytoin, topiramate, and sodium valproate did not $[35,36]$. The antinociceptive effects of antiepileptics appeared to be related to their nerve conduction inhibitory actions.

Frog sciatic nerve CAPs examined in the present study were inhibited by levobupivacaine with an $\mathrm{IC}_{50}$ value of
$0.23 \mathrm{mM}$, a value almost comparable to that $(0.22 \mathrm{mM})$ for tonic inhibition of frog CAPs by this drug [25] and also to that $(0.264 \mathrm{mM})$ for tonic inhibition by this drug of voltage-gated $\mathrm{Na}^{+}$-channel currents recorded at $-100 \mathrm{mV}$ in GH-3 neuroendocrine cells [37]. Consistent with a previous report [25], this action was less than that of racemic bupivacaine. This levobupivacaine activity was almost similar to those of lamotrigine and carbamazepine. Figure 6 illustrates a comparison of the effects of antiepileptics (lamotrigine and carbamazepine) with that of levobupivacaine and those of other local anesthetics (lidocaine, ropivacaine, procaine, cocaine, and tetracaine), as reported previously [11-14], in the frog sciatic nerve. When compared with those of other local anesthetics, $\mathrm{IC}_{50}$ values $(0.44-0.50 \mathrm{mM})$ for lamotrigine and carbamazepine were similar to those of lidocaine, ropivacaine, and cocaine $(0.74,0.34$, and $0.80 \mathrm{mM}$, resp.) while 


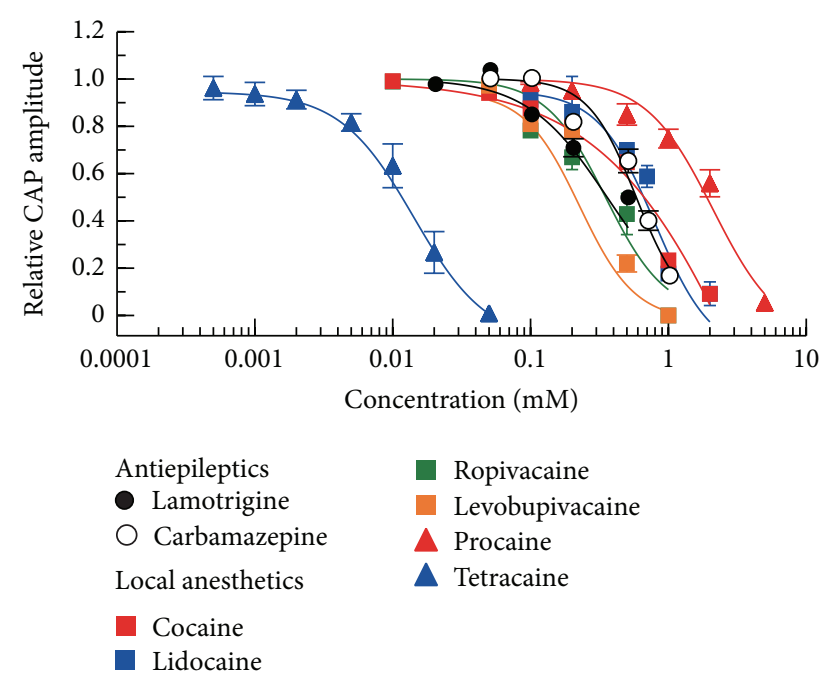

FIGURE 6: Comparison of the effects of antiepileptics (lamotrigine and carbamazepine) on frog sciatic nerve CAPs with those of local anesthetics (levobupivacaine, lidocaine, ropivacaine, procaine, cocaine, and tetracaine). The peak amplitude of CAP recorded from sciatic nerve fibers treated with each of the chemicals at various concentrations for $20 \mathrm{~min}$, relative to control, which was plotted against its concentration. The data of local anesthetics except for levobupivacaine (whose data were reproduced from Figure 5(c)(B)) were taken from previous reports [11-14]. The curves for the local anesthetics were drawn according to the Hill equation, while those for lamotrigine and carbamazepine, shown by black lines, were reproduced from Figures $1(\mathrm{~d})$ and $2(\mathrm{a})(\mathrm{C})$, respectively.

being smaller than that $(2.2 \mathrm{mM})$ of procaine and larger than that $(0.013 \mathrm{mM})$ of tetracaine.

\section{Conclusion}

The present study demonstrated that some of antiepileptics used for treating neuropathic pain inhibit nerve AP conduction with an efficacy similar to those of some local anesthetics, especially lidocaine clinically used for its treatment [5-7]. Nerve AP conduction inhibition by antiepileptics may be a measure of antinociception produced by the drugs in the treatment of a kind of neuropathic pain.

\section{Conflict of Interests}

The authors declare that they have no conflict of interests.

\section{References}

[1] H. Merskey, "Clarifying definition of neuropathic pain," Pain, vol. 96, no. 3, pp. 408-409, 2002.

[2] T. S. Jensen, "Anticonvulsants in neuropathic pain: rationale and clinical evidence," European Journal of Pain, vol. 6, no. 1, pp. 6168, 2002.

[3] N. B. Finnerup, S. H. Sindrup, and T. S. Jensen, "The evidence for pharmacological treatment of neuropathic pain," Pain, vol. 150, no. 3, pp. 573-581, 2010.
[4] A. M. Waszkielewicz, A. Gunia, K. Słoczyńska, and H. Marona, "Evaluation of anticonvulsants for possible use in neuropathic pain," Current Medicinal Chemistry, vol. 18, no. 28, pp. 43444358, 2011.

[5] E. Kalso, M. R. Tramèr, H. J. McQuay, and R. A. Moore, "Systemic local-anaesthetic-type drugs in chronic pain: a systematic review," European Journal of Pain, vol. 2, no. 1, pp. 3-14, 1998.

[6] I. W. Tremont-Lukats, V. Challapalli, E. D. McNicol, J. Lau, and D. B. Carr, "Systemic administration of local anesthetics to relieve neuropathic pain: a systematic review and metaanalysis," Anesthesia and Analgesia, vol. 101, no. 6, pp. 1738-1749, 2005.

[7] C. Delorme, M. L. Navez, V. Legout, R. Deleens, and D. Moyse, "Treatment of neuropathic pain with $5 \%$ lidocaine-medicated plaster: five years of clinical experience," Pain Research and Management, vol. 16, no. 4, pp. 259-263, 2011.

[8] J. W. Shin, C. Pancaro, C. F. Wang, and P. Gerner, "Low-dose systemic bupivacaine prevents the development of allodynia after thoracotomy in rats," Anesthesia and Analgesia, vol. 107, no. 5, pp. 1587-1591, 2008.

[9] I. Kirillova, A. Teliban, N. Gorodetskaya et al., "Effect of local and intravenous lidocaine on ongoing activity in injured afferent nerve fibers," Pain, vol. 152, no. 7, pp. 1562-1571, 2011.

[10] R. L. Macdonald, "Cellular effects of antiepileptic drugs," in Epilepsy: A Comprehensive Textbook, J. Engel Jr. and T. A. Pedley, Eds., pp. 1383-1391, Lippincon-Raven Publishers, Philadelphia, Pa, USA, 1997.

[11] R. Katsuki, T. Fujita, A. Koga et al., “Tramadol, but not its major metabolite (mono-O-demethyl tramadol) depresses compound action potentials in frog sciatic nerves," British Journal of Pharmacology, vol. 149, no. 3, pp. 319-327, 2006.

[12] K. Mizuta, T. Fujita, T. Nakatsuka, and E. Kumamoto, "Inhibitory effects of opioids on compound action potentials in frog sciatic nerves and their chemical structures," Life Sciences, vol. 83, no. 5-6, pp. 198-207, 2008.

[13] T. Kosugi, K. Mizuta, T. Fujita, M. Nakashima, and E. Kumamoto, "High concentrations of dexmedetomidine inhibit compound action potentials in frog sciatic nerves without $\alpha_{2}$ adrenoceptor activation," British Journal of Pharmacology, vol. 160, no. 7, pp. 1662-1676, 2010.

[14] D. Tomohiro, K. Mizuta, T. Fujita, Y. Nishikubo, and E. Kumamoto, "Inhibition by capsaicin and its related vanilloids of compound action potentials in frog sciatic nerves," Life Sciences, vol. 92, no. 6-7, pp. 368-378, 2013.

[15] R. H. Foster and A. Markham, "Levobupivacaine: a review of its pharmacology and use as a local anaesthetic," Drugs, vol. 59, no. 3, pp. 551-579, 2000.

[16] X. Xie, T. J. Dale, V. H. John, H. L. Cater, T. C. Peakman, and J. J. Clare, "Electrophysiological and pharmacological properties of the human brain type IIA $\mathrm{Na}^{+}$channel expressed in a stable mammalian cell line," Pflügers Archiv European Journal of Physiology, vol. 441, no. 4, pp. 425-433, 2001.

[17] M. J. McLean and R. L. Macdonald, "Carbamazepine and 10,11-epoxycarbamazepine produce use- and voltage-dependent limitation of rapidly firing action potentials of mouse central neurons in cell culture," Journal of Pharmacology and Experimental Therapeutics, vol. 238, no. 2, pp. 727-738, 1986.

[18] M. L. Vargas-Espinosa, G. Sanmartí-García, E. VázquezDelgado, and C. Gay-Escoda, "Antiepileptic drugs for the treatment of neuropathic pain: a systematic review," Medicina Oral Patologia Oral y Cirugia Bucal, vol. 17, pp. e786-e793, 2012. 
[19] G. Cruccu, G. Gronseth, J. Alksne et al., "AAN-EFNS guidelines on trigeminal neuralgia management," European Journal of Neurology, vol. 15, no. 10, pp. 1013-1028, 2008.

[20] J. Benes, A. Parada, A. A. Figueiredo et al., "Anticonvulsant and sodium channel-blocking properties of novel 10,11-dihydro$5 H$-dibenz $[b, f]$ azepine-5-carboxamide derivatives," Journal of Medicinal Chemistry, vol. 42, no. 14, pp. 2582-2587, 1999.

[21] D. G. Lang, C. M. Wang, and B. R. Cooper, "Lamotrigine, phenytoin and carbamazepine interactions on the sodium current present in N4TG1 mouse neuroblastoma cells," Journal of Pharmacology and Experimental Therapeutics, vol. 266, no. 2, pp. 829-835, 1993.

[22] C. C. Kuo, "A common anticonvulsant binding site for phenytoin, carbamazepine, and lamotrigine in neuronal $\mathrm{Na}^{+}$channels," Molecular Pharmacology, vol. 54, no. 4, pp. 712-721, 1998.

[23] C. W. Huang, C. C. Huang, M. W. Lin, J. J. Tsai, and S. N. Wu, "The synergistic inhibitory actions of oxcarbazepine on voltagegated sodium and potassium currents in differentiated NG10815 neuronal cells and model neurons," International Journal of Neuropsychopharmacology, vol. 11, no. 5, pp. 597-610, 2008.

[24] P. Molnár and S. L. Erdö, "Vinpocetine is as potent as phenytoin to block voltage-gated $\mathrm{Na}^{+}$channels in rat cortical neurons," European Journal of Pharmacology, vol. 273, no. 3, pp. 303-306, 1995.

[25] S. Lee-Son, G. K. Wang, A. Concus, E. Crill, and G. Strichartz, "Stereoselective inhibition of neuronal sodium channels by local anesthetics: evidence for two sites of action?" Anesthesiology, vol. 77, no. 2, pp. 324-335, 1992.

[26] X. Qiao, G. Sun, J. J. Clare, T. R. Werkman, and W. J. Wadman, "Properties of human brain sodium channel $\alpha$ subunits expressed in HEK293 cells and their modulation by carbamazepine, phenytoin and lamotrigine," British Journal of Pharmacology, vol. 171, no. 4, pp. 1054-1067, 2014.

[27] B. Neumcke, J. R. Schwarz, and R. Stämpfli, "A comparison of sodium currents in rat and frog myelinated nerve: normal and modified sodium inactivation," Journal of Physiology, vol. 382, pp. 175-191, 1987.

[28] Y. P. Maneuf, M. I. Gonzalez, K. S. Sutton, F. Z. Chung, R. D. Pinnock, and K. Lee, "Cellular and molecular action of the putative GABA-mimetic, gabapentin," Cellular and Molecular Life Sciences, vol. 60, no. 4, pp. 742-750, 2003.

[29] C. Zona, M. T. Ciotti, and M. Avoli, "Topiramate attenuates voltage-gated sodium currents in rat cerebellar granule cells," Neuroscience Letters, vol. 231, no. 3, pp. 123-126, 1997.

[30] G. Curia, P. Aracri, E. Colombo et al., "Phosphorylation of sodium channels mediated by protein kinase-C modulates inhibition by topiramate of tetrodotoxin-sensitive transient sodium current," British Journal of Pharmacology, vol. 150, no. 6, pp. 792-797, 2007.

[31] A. Chapman, P. E. Keane, B. S. Meldrum, J. Simiand, and J. C. Vernieres, "Mechanism of anticonvulsant action of valproate," Progress in Neurobiology, vol. 19, no. 4, pp. 315-359, 1982.

[32] E. Perucca, "A pharmacological and clinical review on topiramate, a new antiepileptic drug," Pharmacological Research, vol. 35, no. 4, pp. 241-256, 1997.

[33] M. F. M. Braga, V. Aroniadou-Anderjaska, H. Li, and M. A. Rogawski, "Topiramate reduces excitability in the basolateral amygdala by selectively inhibiting GluK1 (GluR5) kainate receptors on interneurons and positively modulating $\mathrm{GABA}_{A}$ receptors on principal neurons," Journal of Pharmacology and Experimental Therapeutics, vol. 330, no. 2, pp. 558-566, 2009.
[34] C. Y. Lee, W. M. Fu, C. C. Chen, M. J. Su, and H. H Liou, "Lamotrigine inhibits postsynaptic AMPA receptor and glutamate release in the dentate gyrus," Epilepsia, vol. 49, no. 5, pp. 888-897, 2008.

[35] G. Blackburn-Munro, N. Ibsen, and H. K. Erichsen, "A comparison of the anti-nociceptive effects of voltage-activated $\mathrm{Na}^{+}$ channel blockers in the formalin test," European Journal of Pharmacology, vol. 445, no. 3, pp. 231-238, 2002.

[36] H. E. Shannon, E. L. Eberle, and S. C. Peters, "Comparison of the effects of anticonvulsant drugs with diverse mechanisms of action in the formalin test in rats," Neuropharmacology, vol. 48, no. 7, pp. 1012-1020, 2005.

[37] M. Vladimirov, C. Nau, W. M. Mok, and G. Strichartz, "Potency of bupivacaine stereoisomers tested in vitro and in vivo: biochemical, electrophysiological, and neurobehavioral studies," Anesthesiology, vol. 93, no. 3, pp. 744-755, 2000. 

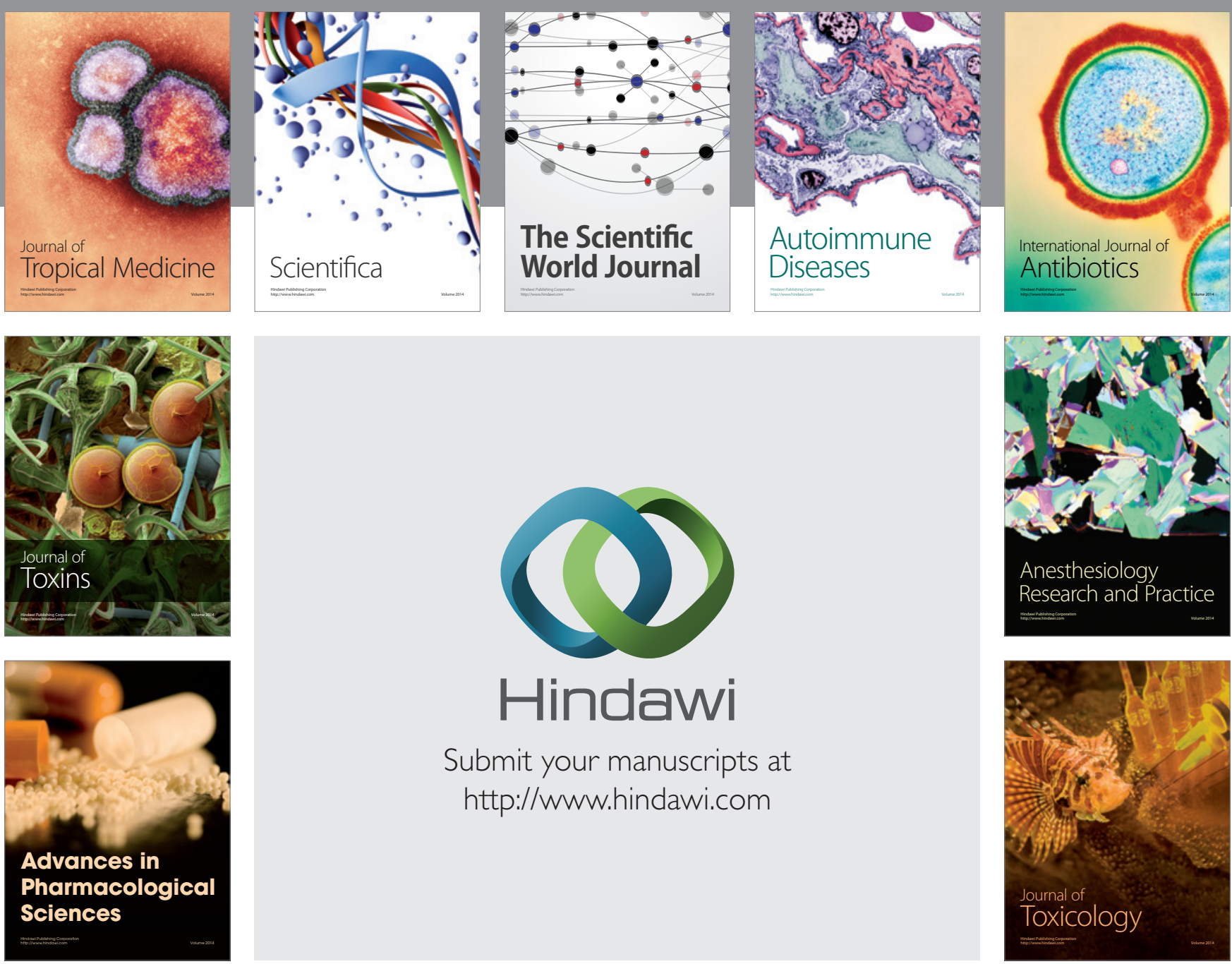

\section{Hindawi}

Submit your manuscripts at

http://www.hindawi.com
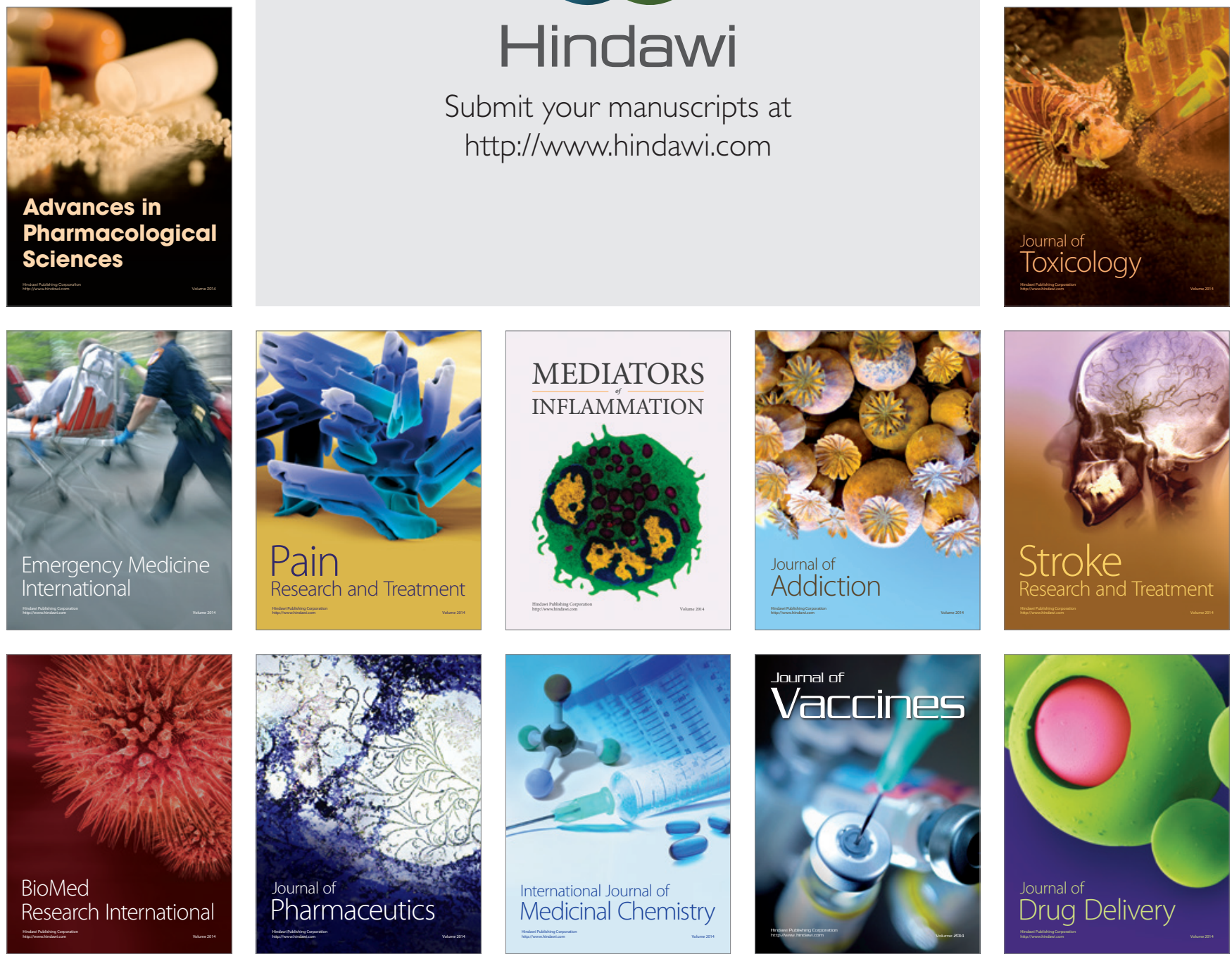